$\begin{array}{ll}\begin{array}{l}\text { Open door } \\ \text { European meeting } \\ \text { gets the Swede smell } \\ \text { of success } \\ p 5\end{array} & \begin{array}{l}\text { Kill or cure? } \\ \text { Feathers fly in } \\ \text { Thailand over } \\ \text { bird flu vaccine } \\ p 6\end{array}\end{array}$

\title{
Ethics review slams government panels over conflicts of interest
}

Emma Marris, Washington

A US government ethics office is demanding that agencies comply more fully with rules requiring experts on advisory panels to declare potential conflicts of interest.

Some two-thirds of scientists, engineers, lawyers and other specialists on the panels don't fill out any financial conflict-of-interest paperwork. For years, government agencies have chosen to give them a special job title - 'representative' - that exempts them from declaring any conflicts of interest they may have.

The loophole affects hundreds of panels that advise the government on everything from lead concentrations in drinking water to the safe disposal of nuclear weapons.

Most of the panels were set up under the Federal Advisory Committee Act (FACA) a pioneering 1972 law passed to ensure that advice is given to the government publicly and transparently. But a congressional audit earlier this year found that agencies have come to flaunt the spirit of the law by using a bureaucratic dodge that prevents many possible conflicts from being declared.

FACA panels on contentious issues such as climate change, earthquake risk assessment or food safety are watched avidly by interest groups and the press. But the audit said that committees offering advice on these very topics frequently consisted entirely of representatives who didn't have to declare any conflicts of interest.

"The system has got completely out of whack over the years," says Merrill Goozner, an analyst at the Washington-based Center for Science in the Public Interest, a watchdog group specializing in dietary issues. He says he hopes that the memo from the Office of Government Ethics, which was released in July as a follow-up to the audit published by the Government Accountability Office (GAO) in April, will spur reform. "Everyone is now on notice," he says.

Jennifer Sass, a spokeswoman for the Natural Resources Defense Council, an environmental group, says that everyone giving scientific advice should be asked about conflict of interest, and that those with a clear bias should be denied voting rights on the panels.

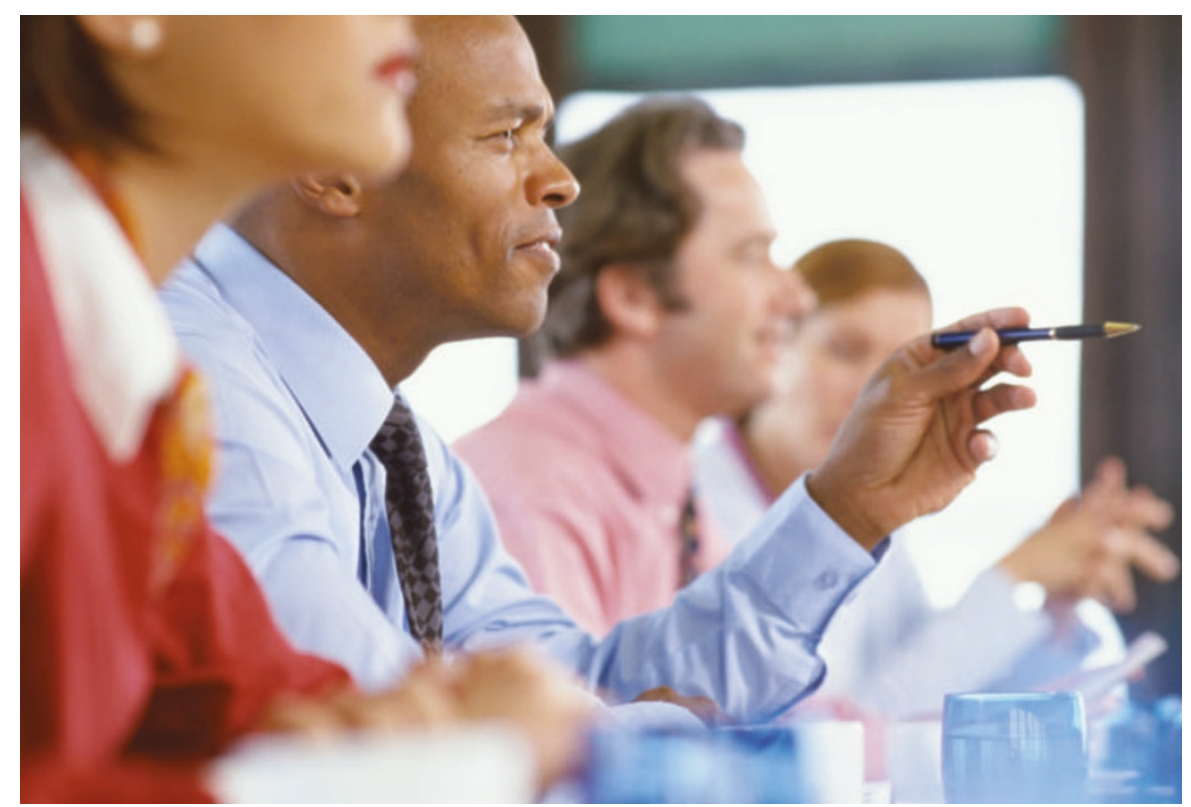

A representative sample? Critics are worried about the financial interests of US advisory panel members.

The congressional audit was requested by two Democratic members of Congress who were following up on reports that the Bush administration was filling its advisory committees with political allies. But the audit instead highlighted the practice of appointing many panel members as representatives - a practice it described as "long-standing and firmly rooted in agency culture".

\section{Inherent bias}

Representatives are supposed to stand for an industry or interest group - a panel on food safety, for example, might have a representative from the beef industry. Because their bias is obvious and expected, they don't fill out conflict-of-interest paperwork. But many agencies overuse the designation, according to the GAO, and the departments of the interior, energy and agriculture appoint all panel members as representatives, including people specifically chosen to provide unbiased scientific advice.

The ethics-office memo is already having some effect, according to agency officials. Shayla Simmons, ethics official at the Department of the Interior, says her depart- ment is now reviewing each new committee member. She says that many panel members just aren't expected to give objective advice. "We will still have the majority of the people on committees serving as representatives," she says, "because most people are representing some interest."

Julie Quick, a spokeswoman from the Department of Agriculture, says that change is in the air there also. "We are considering a model used by other agencies," she says, in which academic scientists can no longer be appointed as representatives. A spokesperson for the energy department, which oversees panels dealing with everything from nuclear clean-up to research priorities in physics, would say only that the issue was "under review".

In a report due out this November on presidential advice, the National Academy of Sciences is expected to take up the question of how conflicts of interest are declared. The academy's multi-stage process for assessing conflicts on its own panels has been cited by critics of the federal system as a possible model, although others say the procedures are inconsistently applied in practice. 